\title{
Are We Living in LA (P)LA Land? Reporting on the Practice of 30 STEM Tutors in Their Use of a Learning Analytics Implementation at The Open University
}

\author{
Tom Olney ${ }^{1}$, Steve Walker ${ }^{2}$, Carlton Wood ${ }^{3}$, Anactoria Clarke ${ }^{4}$
}

\begin{abstract}
Most higher education institutions view their increasing use of learning analytics as having significant potential to improve student academic achievement, retention outcomes, and learning and teaching practice but the realization of this potential remains stubbornly elusive. While there is an abundance of published research on the creation of visualizations, dashboards, and predictive models, there has been little work done to explore the impact of learning analytics on the actual practice of teachers. Through the lens of social informatics (an approach that views the users of technologies as active social actors whose technological practices constitute a wider socio-technical system) this qualitative study reports on an investigation into the practice of 30 tutors in the STEM faculty at Europe's largest distance learning organization, The Open University UK (OU). When asked to incorporate learning analytics (including predictive learning analytics) contained in the Early Alert Indicator (EAI) dashboard during the 2017-2018 academic year into their practice, we found that tutors interacted with this dashboard in certain unanticipated ways and developed three identifiable "shadow practices".
\end{abstract}

\section{Notes for Practice}

- There is a lack of evidence in the literature exploring specifically how tutors interpret and action learning analytics when they are made available to them.

- In this implementation, STEM tutors reacted in several ways: 1) they used the predictive learning analytics in five distinct ways and their interpretation and associated actions were subjective and context driven; 2) they considered descriptive learning analytics to be more useful than predictive learning analytics when presented alongside one another; 3) they accessed the learning analytics at specific times despite different module contexts; and 4) they did not consider this implementation to have significantly contributed to their practice in supporting students.

- Higher education institutions hoping to introduce actionable learning analytics implementations should be aware of the challenges inherent in using complex, non-transparent predictive algorithms, decontextualized data, and socio-technical systems that do not directly address the problems tutors face.

- Social informatics, and the identification of "shadow practices," should be considered as a valuable methodological approach when attempting to evaluate tutor practice with technologies.

\section{Keywords}

Tutor practice, learning analytics implementation, social informatics, shadow practice

Submitted: 09/06/20 — Accepted: 09/02/21 — Published: 01/10/21

Corresponding author ${ }^{1}$ Email: tom.olney@open.ac.uk Address: Faculty of STEM, The Open University, Walton Hall, Milton Keynes, MK67AA, UK. ORCID ID: https://orcid.org/0000-0003-1132-4230

${ }^{2}$ Email: steve.walker@open.ac.uk Address: Faculty of STEM, The Open University, Walton Hall, Milton Keynes, MK67AA, UK. ORCID ID: https://orcid.org/0000-0002-6838-8334

${ }^{3}$ Email: c.k.wood@open.ac.uk Address: Faculty of STEM, The Open University, Walton Hall, Milton Keynes, MK67AA, UK. ORCID ID: https://orcid.org/0000-0001-5567-1694

${ }^{4}$ Email: anactoria.clarke@open.ac.uk Address: Faculty of Arts \& Social Sciences, The Open University, Walton Hall, Milton Keynes, MK67AA, UK. ORCID ID: https://orcid.org/0000-0002-5616-2610 


\section{INTRODUCTION}

Changes in the higher education policy environment over the last few years have placed an increasing emphasis on evaluating and reporting university business through data and analytics. For example, new requirements in the UK require higher education institutions (HEIs) to produce detailed metrics for the government-established Office for Students (OfS) as laid out in the Teaching Excellence and Student Outcomes Framework, known as TEF (TEF, 2019).

Within this context, the view that learning analytics has the potential to improve education seems to be widely accepted. We use the term learning analytics, and its acronym LA, here in accordance with the widely accepted definition provided by the Society for Learning Analytics Research (SoLAR) at the 1st International Conference on Learning Analytics and Knowledge (LAK) and referenced by Long and Siemens (2011, p. 34): "Learning analytics is the measurement, collection, analysis, and reporting of data about learners and their contexts, for the purposes of understanding and optimizing learning and the environments in which it occurs."

A subset of LA can be seen in the more recent development of predictive learning analytics (PLA) that can utilize machine learning and artificial intelligence to predict student behaviour and/or outcomes. Other subsets of LA include descriptive learning analytics, which is concerned with describing and analyzing historical student data, and prescriptive learning analytics, which is concerned with enabling future decision-making (Daniel, 2015). Our experience suggests that the inclusion of these different types of LA in the same implementation produce different user behaviours and that being scrupulous and differentiating between them is important.

The UK Higher Education Commission's 2016 From Bricks to Clicks: The Potential of Data and Analytics in Higher Education report concludes that LA "has enormous potential to improve the student experience at university, by allowing the institution to provide targeted and personalized support and assistance to each student" (Shacklock, 2016, p. 4). The UK digital services not-for-profit organization, Jisc's 2016 report, Learning Analytics in Higher Education, also concluded that "Learning analytics has the potential to transform the way we measure impact and outcomes in learning environments" (Sclater et al., 2016, p. 11).

Consequently, HEIs have devoted significant resources to implementing LA, driven by a belief that LA will allow for improvements in areas such as capturing and sharing learning designs, providing better academic support and feedback for students, increasing student satisfaction rates, enhancing teaching and learning practice, capturing student attendance data, and improving retention (Clow, 2013; Hu et al., 2014; Dalziel et al., 2016; Olney, Rienties, \& Toetenel, 2019; Shacklock, 2016; Arthars et al., 2019; Tanes et al., 2011; Foster, 2015; Agnihotri \& Ott, 2014; Herodotou et al., 2019b).

However, realizing this potential has so far been elusive and there is a growing acceptance that, to date, "what is most evident is that learning analytics has immense promise that is yet to be fully realized" (Lodge, Horvath, \& Corrin, 2019, p. 7). More critical voices have started to argue that there should be more focus on how implementations of LA interact with the world around them and the human users of data in order to achieve the aspirations previously outlined (Wise \& Vytasek, 2017; Bartimote et al., 2019; Lodge, Horvath, \& Corrin, 2019; Ferguson et al., 2019).

For example, for some, LA downplays the role of education as a "profoundly emotional and human process" (Castaneda \& Selwyn, 2018, p. 4), introduces non-human elements to learning, such as demographic data, over which the student has little control (Kop, Fournier, \& Durand, 2017), and can only be understood properly by placing its study within the wider context of an "algorithmically pervaded society" (Knight \& Buckingham Shum, 2017, p. 17). In this view, as part of a range of tools assisting in the "ongoing digitizations of higher education," LA is best framed in "problematic — rather than celebratory terms" (Castaneda \& Selwyn, 2018, p. 8).

Therefore, for these reasons, we fundamentally agree with the premise that "Essentially, it is not easy to use technology to analyze learning or use predictive analytics to advance learning" (Kop et al., 2017, p. 322) and that any attempted evaluation of LA should consider the human factor.

LA implementations are examples of information systems embedded in particular social and organizational settings. Rather than viewing LA as a technology that will lead unproblematically to positive outcomes for students, we look at LA as technology-in-use where outcomes emerge from the interaction of the tool with the varied practices of social actors. Our approach is informed by the social informatics tradition of studying information systems (e.g., Kling, 2007; Lamb \& Kling, 2003; Orlikowski \& Gash, 1994; Sawyer \& Hartswood, 2014) and educational technologies (Creanor \& Walker, 2012; McCoy \& Rosenbaum, 2019; Walker \& Creanor, 2009; White \& White, 2016). Any outcomes for students are not reliant solely, or even primarily, on LA applications and models, but on the outcomes of the entire sociotechnical network, including tutors, materials authors, academic managers and so on, in which they are located. Each group of actors incorporates LA into existing practices in ways that may not have been understood or intended by the designers but which, we posit, are central to the outcomes as experienced by learners. The focus of this study, then, has been on how key groups of actors have responded to the technology. 
Through individual semi-structured interviews, this study aims to answer the following four research questions on the use of the EAI dashboard in the STEM faculty at The Open University:

RQ1: When did the tutors use the LA in the EAI dashboard?

RQ2: Which types of LA did the tutors use in the EAI dashboard?

RQ3: Why and how did the tutors use the LA in the EAI dashboard?

RQ4: What contribution did the EAI dashboard make to how tutors supported their students?

We also ask the broader question: By failing to evidence how LA is actually used by teachers in order to achieve this "potential" have we created an illusory LA (P)LA land for ourselves?

\section{Background and Context}

\subsection{The Open University Model for Distance Education}

The OU has around 170,000 students studying with it at any given time and, as such, is the largest university in Europe. Founded in 1969, its mission statement "Open to All" reflects the values of inclusivity, innovation, and responsiveness.

The OU is a distributed institution. Academics are responsible for designing and creating the learning materials that form "modules" that run for 24 or 32 weeks. These materials take the place of conventional lectures and while students are studying, the academics work alongside academic-related colleagues, known as "curriculum managers" (CM), to form "module management teams." Collectively, they are interested in the tasks of monitoring, refinement, and improvement that goes along with any other teaching situation. The Faculty of Science, Technology, Engineering and Mathematics (STEM), in which this project took place, manage around 140 modules comprising about $40 \%$ of the overall curriculum at the OU.

Students typically study via a combination of printed books and online materials presented on a Moodle-based virtual learning environment (VLE) developed by the OU; they need to complete 360 credits in order to pass their degree qualification.

Crucially to this study, day-to-day academic support for students is provided by tutors. Tutors typically work part-time for the OU, often combining this work with other employment. They work from home and keep in contact with their students via phone, face to face, email, and online tutorials. Tutors help students to navigate the learning materials and support assessed work.

Pastoral support is also provided via the Student Support Teams (SST), staffed by learning advisors and educational guidance counsellors. Since SST staff provide support outside the academic remit of individual modules — for example, giving financial advice and pastoral support for students with additional requirements - tutors will often refer students to them. This SST support is typically provided by telephone or email.

\subsection{Approaches to Using LA at The Open University}

The OU has been active in developing many different, but linked, LA implementation approaches in order to develop an "analytics mindset" that encourages and supports staff in evidence-based decision-making throughout their routine work (Sclater et al., 2016). Between 2014 and 2018, the OU "Analytics Project" developed three initiatives in parallel. In one, the technical constraints of accessing, cleaning, and extracting useful LA from the existing data warehouse needed to be overcome and the data visualized in a suite of dashboards. To support the use of these dashboards the Analytics4Action (A4A) framework was designed to guide module management teams in their interpretation of the LA and make evidence-based actions (Rienties et al., 2016, 2018; Hidalgo, 2018). The first "Ethics Policy on Learning Analytics" in the tertiary education sector was also developed (Slade \& Boroowa, 2014). LA has also been embedded in learning design approaches (Conole, 2012; Nguyen et al., 2017; Olney, Rienties, \& Toetenel, 2019).

Based on two already-existing predictive models - the Student Probabilities Model (SPM; Simpson, 2006; Calvert, 2014) and OU Analyze (OUA) - the Early Alert Indicator (EAI) project team was tasked between 2016 and 2019 with advising the OU how it might best use PLA, and to generate evidence of what works and what does not. The OUA PLA model has been developed to guide early interventions with students who might be considered "at risk" of not submitting their next assignment. The system employs three machine-learning methods to develop four predictive models: 1) Bayesian classifier, 2) classification and regression tree, 3) k-nearest neighbours (k-NN) with demographic data, and 4) k-NN with virtual learning environment (VLE) data. The predictions use both demographics (such as age, gender, geographic region, previous education) and student interactions with the VLE (such as forum, content, resource, glossary, wiki, etc.) to create a module "fingerprint" (see Kuzilek et al., 2015 for more details).

From 2016, PLA visualizations based on OUA were combined with two other descriptive LA visualizations and made available to module management teams and tutors via the EAI dashboard:

VLE engagement data (individual student level for tutor group and aggregated for module level) presented as clicks per week in a line graph over time. DESCRIPTIVE LA (Figure 1). 
Tutor Marked Assessment (TMA) scores (individual student level for tutor group) and rates of submission (aggregated for module level) presented as a percentage. DESCRIPTIVE LA (Figure 2).

OUA PLA presented as a traffic-light system to pinpoint, in red, students predicted not to submit their next TMA; in amber, those who are likely not to submit their next TMA; and in green, those who are predicted to submit. PREDICTIVE LA (Figure 2).

\section{Declan Pagac AXXXXXXX - Week $26 \quad$ Last login as recorded on ou systems - 03/04/2019}

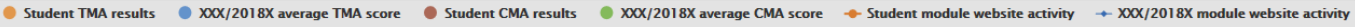

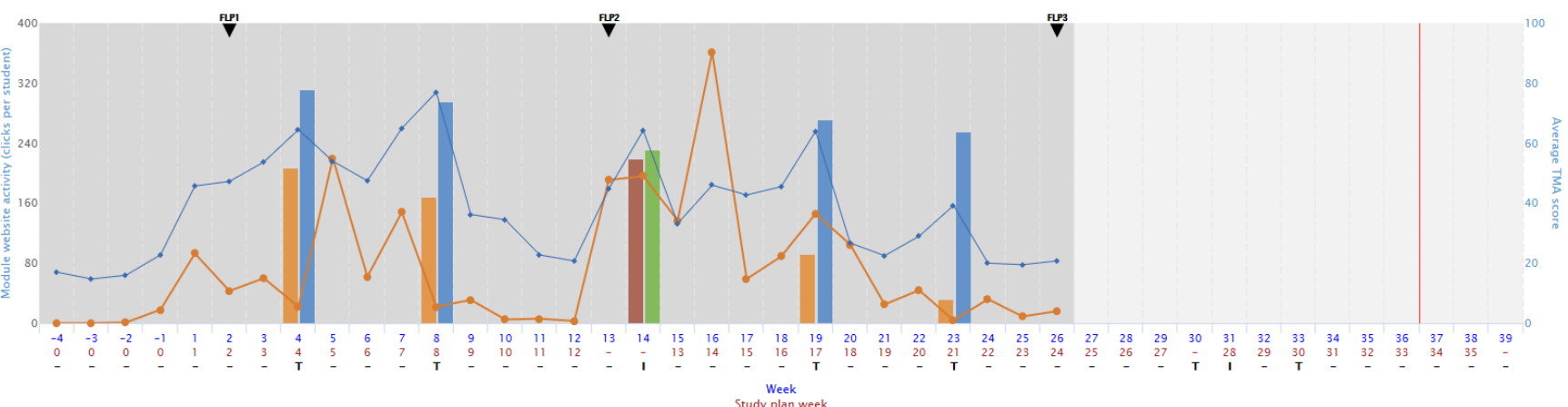

Figure 1. Screenshot showing anonymized student VLE engagement LA from EAI dashboard.

(Student names are fictional)

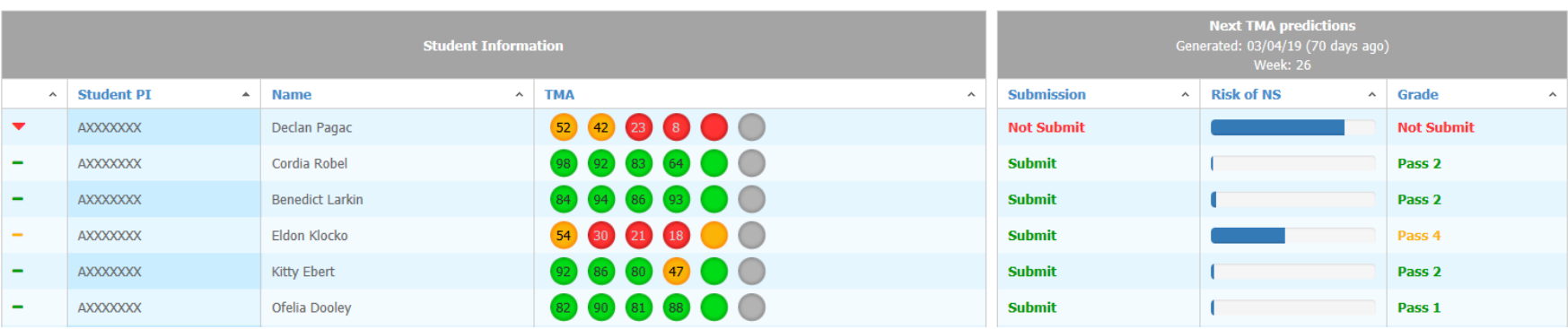

Figure 2. Screenshot showing anonymized student TMA score LA and OUA PLA from EAI dashboard. (Student names are fictional)

Thus, the OU uses several kinds of analytics including both descriptive and predictive LA. These LA may potentially allow for fine-grained analysis and evidence-based interventions in the areas previously outlined, but they also exist in a complex institutional socio-technical system whose components compete for the limited attention of both tutors and module management teams.

\section{LITERATURE REVIEW}

As described earlier, the OU employs a distinct distance education model in which teaching is primarily carried out by the staff group known as tutors. While module management teams also play an important role in this activity, tutors most frequently engage directly with OU students so it is tutor practices we are concerned with in this study. Therefore, for the purposes of this more general literature review, references to "teachers" and "teaching" should be taken to refer to the activities of tutors.

Improving our understanding of how tutors interact with LA is crucial if any of the "potential" of LA is to be realized. To move past the challenges of gathering, visualizing, and presenting data sets, the ability of teachers to then interpret, apply, and ultimately action LA will be the ultimate measure of their success (Wise \& Vytasek, 2017; Bartimote et al., 2019; Lodge, Horvath, \& Corrin, 2019). 
The idea that LA can only be as useful as the actions it instigates has been recognized in the implementation of the Student dashboard (Foster, 2015) and STAR dashboard (Agnihotri \& Ott, 2014). Interviews with eight teachers - in the welldocumented example of the Signals system at Purdue University — revealed a variety of approaches to actioning the data they were supplied with. Despite teachers generally finding the technology useful in communicating to students where they stood early in the semester, none were confident about the timing and proportion of the positive and negative feedback they sent to students (Tanes et al., 2011).

The observation that division and difficulty in institutional collaboration "between those who know how to extract data and what data is available, and those who know what data are required and how it would best be used" (Daniel, 2015, p. 916) is of particular interest to us in adopting this study, also highlighted by Klein et al. (2019). Indeed, any LA "solutions" must consider "human decision-making and consequent actions" and should stress the interrelatedness of both the social and technical aspects, each of which affects the other in the design (van Harmelen \& Workman, 2012, p. 4).

LA implementations must take the importance of educational theory seriously in the design and evaluation of technologies so that, "generating sound pedagogical knowledge via learning analytics relies on a practice informed by and situated in defensible [theoretical] frameworks" (Bartimote et al., 2019, p. 23). The application of theory will allow teachers to explain what they observe in learning analytics, make sound educational decisions, and provide the underpinning knowledge to enable transference of understanding from one context to another (Knight \& Buckingham Shum, 2017; Jivet et al., 2018).

Despite the importance of this field, there is a deficit in the literature exploring it. Schwendimann et al. (2017) were unable to identify any studies that set out to evaluate the actions of teachers when given LA with sample sizes of over 10 in authentic university settings. Actions identified in these small studies, such as "adjusting or adopting different teaching methods" (Hu et al., 2014), were so general as to be meaningless. Herodotou et al. (2019a; 2020) also interviewed six and eight self-selecting tutors respectively on their use of the EAI dashboard. Due to their specific relevance, these findings are dealt with at length in the discussion section. Quantitative analyses from two other OU studies (Herodotou et al. 2019b; 2019c) reported tutor levels of engagement with the EAI dashboard - but referred to as OUA PLA — was positively associated with student learning outcomes.

Schwendimann et al. (2017), Jivet et al. (2018), and Herodotou et al. (2109a) agree that future focus in LA research should "provide details about the (learner and/or teacher) practices that developed (or are expected) using the dashboard" (Schwendimann et al., 2017, p. 38).

\section{Methodology}

\subsection{Design}

Social informatics is used here loosely to refer to transdisciplinary approaches that consider information and communication technologies less as discrete systems with predictable impacts on the world, but rather that emphasize their creation and use in typically pre-existing complex ecologies of people, practices, artefacts, and data sources. The earlier description of LA approaches at the OU, and previous work on how OU tutors $(\mathrm{n}=7)$ use the existing LA tools available to them (Walker et al., 2019), reveals that the tutor experience in using LA at the OU is, in line with social informatics thinking, far from a "green field" site. Any new LA implementations must take account of this existing ecology and practices if it has any hope of being taken up and used "in the wild."

In these socio-technical networks, users are not passive recipients of technologies, free simply to adopt or not adopt a technology, as in classical understandings of the diffusion of innovation. Rather, users are social actors with the agency to adapt and use technologies in potentially diverse ways in their particular contexts that may not have been foreseen or intended by designers or managers (Lamb \& Kling, 2003). In this view, a tutor using educational technology to support students is one such social actor, trying to navigate, for example, at least four separate complex challenges (context, priorities, possible options, and enacting change), which are largely context driven and subjective, in order to make evidence-based decisions about their teaching practice based on LA representations (Wise \& Vytasek, 2017).

The interview instrument employed here was structured to guide a 30-minute interview and reflect this approach. It was structured as a set of questions with associated prompts for use where necessary. Importantly, the schedule was designed to be open to unanticipated responses such that respondents could describe their practice as far as possible in their own terms. The questions covered the following areas: first, a distinction was drawn between the PLA and descriptive LA components of the EAI dashboard and these components were treated separately. For each component tutors were asked to reflect on (a) how they used the EAI LA (triggers for use, usability, frequency of use), (b) how they interpreted and/or applied the EAI LA (identification of at-risk students, diagnosis of issue, intervention choice), (c) how they selected and/or triangulated LA from wider or existing sources, and (d) what training and support they had received. In particular, (b) used the preliminary model proposed by Walker et al. (2019) as a structure. 
By documenting and comparing tutor practice before and after the introduction of the EAI dashboard, we argue that a social informatics framework provides insight into why the term "potential" remains prevalent in the LA literature. Further, we believe this approach will assist in a more nuanced exploration of the persistent gap that exists between the visions of developers and managers, and the experience of implementation - the unsubstantiated LA (P)LA Land referred to in our provocative title.

\subsection{Participants}

Ten STEM faculty module management teams, representing a total population of around 7,500 students and roughly 375 tutors at module start, volunteered their modules to take part in this study during the 2017-2018 academic year. Individual tutor involvement in the pilot was not compulsory and access to the EAI dashboard in STEM was given to tutors who had attended a 60-minute online training session provided by the EAI project team. This training consisted of a slideshow briefing with screenshots of the EAI dashboard, suggestions about what using the LA contained in it could add to practise, and some benefits and drawbacks. In a few cases, module management teams provided suggested guidance on use, although most did not.

The OUA model has been used to generate data for OU tutors for four years. Adoption rates have varied as this work has been scaled up. In 2015-2016, the percentage of tutors who accessed OUA data in some form compared to those with access was $89.7 \%$ (52/58). In 2016-2017, this was 33.1\% (234/706); in 2017-2018 (when this study took place) it was 57\% (171/300); and in 2018-2019 it was 33.2\% (1159/3491). The 30 STEM participants in this study represent about 10\% of the larger, 300member cohort of OU tutors with access in the 2017-2018 academic year (Herodotou et al., 2020). Although referred to as a "pilot" here, the numbers and timing demonstrate the considerable scale of this work; it is reasonable to assume that tutors would have regarded the embedding of the EAI dashboard as a probable outcome of the EAI project. Nine of the participating tutors reported that they had used OUA data before.

The modules represented a variety of subject content, study level, and experience using LA. They were drawn from four schools within the STEM faculty: Engineering \& Innovation $(n=3)$, Life, Health and Chemical Science ( $n=4)$, Physical Science $(\mathrm{n}=2)$, and Environment, Earth \& Ecosystems Science $(\mathrm{n}=1)$. Five were first year modules, three were second year, and two were third year. Two modules were being presented for the first time.

A random list of tutors was generated by a computer program. They were then contacted by the STEM project team and invited to be interviewed. This approach did not generate enough positive responses, however, so the invitation was extended to all piloting tutors, which resulted in 30 tutors from six of the piloting modules agreeing to be interviewed. Despite not being ideal, this self-selection is not necessarily problematic. Any positive bias towards the use of the technology in the sample only really serves to strengthen our contention that the use of the EAI dashboard was limited even more than our findings suggest. The collected and reported demographics suggest that the tutor sample was broadly representative (see Table 1).

Table 1. OU Tutor Demographics

\begin{tabular}{llr}
\hline & Range & No. of tutors \\
\hline Length of service & $0-5$ yrs. & 2 \\
& $6-10$ yrs. & 14 \\
& $11-15$ yrs. & 4 \\
& $16-20$ yrs. & 3 \\
& $21+$ yrs. & 6 \\
& undeclared & 1 \\
\hline No. of modules currently teaching & 1 module & 5 \\
& $2-4$ modules & 17 \\
& $5-7$ modules & 6 \\
& $8-10$ modules & 2 \\
\hline No. of piloting modules currently teaching & 1 module & 19 \\
& 2 modules & 6 \\
& 3 modules & 4 \\
& 4 modules & 1 \\
\hline Previous experience with EAI dashboard & Yes & 9 \\
& No & 21 \\
\hline Regional UK location & North & 11 \\
& South & 9 \\
& East & 6 \\
& West & 3 \\
& undeclared & 1 \\
\hline
\end{tabular}


Thirty-minute, semi-structured interviews were completed using Skype for Business by two other tutors employed by the STEM project team who had been briefed on the aims of the project and the basic functionality of the EAI dashboard.

\subsection{Analysis}

For all 10 modules, data representing the number of times tutors logged into the EAI dashboard per week was extracted by the EAI project team from the EAI dashboard into Tableau and repurposed in Excel by the STEM project team. The interviews were recorded, transcribed by an external professional transcription service, and uploaded to NVivo 12. Each tutor was allocated a unique anonymous identifier code, made up of an ID number, their EAI dashboard module, the number of years of experience as a tutor, and the total number of modules they taught.

As a first step, each member of the STEM project team individually reviewed the interview transcriptions in an inductive thematic analysis (Braun \& Clarke, 2006; Maguire \& Delahunt, 2017). The results of this thematic analysis were discussed, compared, and used to finalize the RQs. Five interview transcripts were then coded directly to the RQs in NVivo 12 by Author 1 , grouping similar responses together depending on the nature of the RQ and (when appropriate) whether the response was positive or negative. The findings section below is structured to reflect this framework. Inter-coder consensus and reliability was established through discussion and amendment with Author 2 on these five transcripts before Author 1 proceeded with the remaining transcripts. The coding of all transcripts was discussed between Author 1 and Author 2 and then finalized.

\section{FINDINGS}

\section{RQ1: When did the tutors use the LA in the EAI dashboard?}

When asked at interview, 15 tutors were able to suggest how many times they felt they had accessed the EAI dashboard over the course of the presentation. Four said between one and 10 times, 10 said between 10 and 15 times and one responded over 15 times. Fifteen of the tutors were clear that they had accessed the EAI dashboard more heavily at the start of the module, and their access had tailed off after that. It was common for tutors to explain that this pattern of behaviour was driven by a desire to get to know their group as early as possible and to see "how the students were engaging" [T13-D-09-08] with the VLE. The presence of VLE activity served as a reassurance: "if they are on the website [at the start] and visiting, it's less of a panic and I can just chase them up by email. If they're not on the website, it's something I've got to look at" [T17-F-05-03]. The first few weeks of the module, especially before the first assessment point, were typically for tutors "the time the students need the most support" [T01-B-22-10].

This finding was supported by the user engagement data extracted from the EAI dashboard. This data showed that in absolute numbers and averaged across the 10 modules, the number of times tutors engaged with the EAI dashboard roughly halved every 11 weeks (see Table 2). This pattern is consistent within the individual modules as well.

Two tutors indicated that they continued to access the EAI dashboard on a weekly basis throughout the module, building it into a regular routine.

Table 2. Absolute Number of Unique Weekly Tutor Visits to EAI Dashboard per Module per 11-Week Block (Table shows unique tutor access per week but NOT unique tutor access per 11-week block)

\begin{tabular}{lcrr}
\hline Module & \multicolumn{3}{c}{ Weeks } \\
& 1 to 11 & 12 to 23 & 24 to end \\
\hline $\mathrm{A}$ & 131 & 74 & 39 \\
$\mathrm{~B}$ & 190 & 85 & 64 \\
$\mathrm{C}$ & 43 & 26 & 20 \\
$\mathrm{D}$ & 43 & 23 & 17 \\
$\mathrm{E}$ & 30 & 19 & 16 \\
$\mathrm{~F}$ & 82 & 44 & 13 \\
$\mathrm{G}$ & 99 & 34 & 31 \\
$\mathrm{H}$ & 94 & 59 & $\mathrm{n} / \mathrm{a}^{*}$ \\
$\mathrm{I}$ & 35 & 15 & $\mathrm{n} / \mathrm{a}^{*}$ \\
$\mathrm{~J}$ & 18 & 5 & 5 \\
\hline Totals & 765 & 384 & 205 \\
& *module length is 24 weeks.
\end{tabular}

\section{RQ2: Which types of LA did the tutors use in the EAI dashboard?}

VLE engagement data and the TMA assessment submission data (both descriptive LA) were, in general, considered much more useful than the PLA when presented alongside one another in this implementation. Twelve tutors made positive 
references about the use of the descriptive LA, typically expressing that it helped them to monitor student interaction with the VLE and raise questions such as if "a student was spending large periods of time offline I would query whether that would equate to regular study" [T08-C-07-06]. Three tutors felt the detailed VLE activity data offered them little new information that could not already be accessed from their student list.

Twenty-five of the tutors interviewed made negative comments about the OUA PLA in the EAI dashboard. Many of these comments referenced concerns about the frequency of the false positives (a student predicted to submit who does not) and false negatives (a student predicted not to submit who does) that it generated. These tutors reported low levels of confidence in the PLA with comments such as "I don't trust OU Analyze" [T24-H-03-03] and "I haven't been relying on it as a predictive tool" [T13-D-09-08] commonplace. They were highly critical of the predictions, describing them as "as a bit too crude" [T10-CXX-06], "a little bit of a nonsense" [T15-F-13-03], "useless" [T16-F-10-02], "inaccurate" [T18-F-10-02], and "completely wrong" [T28-J-37-04]. For most tutors in this group, the predictions were unhelpful but dispensable in the face of personal knowledge or experience. However, some went further than that: "I found its prediction properties to be not very useful and actually sort of [...] the opposite of that. It was giving me very misleading information" [T08-C-07-06]. However, five tutors made more positive comments about the PLA, noting that it "will flag up things that it's worth following up" [T06-C-08-02] and that, in their experience, it did well "in matching what I know about the students" [T13-D-09-08].

Of those tutors who reported that they stopped accessing the EAI dashboard regularly, many did so when they considered that other already-existing methods of identifying students at risk as being as helpful or more helpful (the "last VLE login" flag and email were common examples) or when they no longer considered the EAI dashboard useful in telling them anything extra about their students. Twenty-six tutors explicitly mentioned continuing to use other forms of LA (these other LA sources are detailed in Walker et al., 2019; they included forums, student flags, and previous study history) to triangulate the data the EAI dashboard provided. Frequently, they also returned to personal and contextualized methods of recording that information. For example, "for me just a simple spreadsheet of who has been active, who hasn't and who has been contacted that week was working better for me [...] so I went back to that really" [T09-C-07-02].

While a couple of tutors indicated they had made the EAI dashboard a cornerstone of their practice, the majority were not won over by the detail on offer, and continued instead with their tried and tested methods.

\section{RQ3: Why and how did the tutors use the LA in the EAI dashboard?}

It was possible to identify five distinct ways in which the tutors interviewed were triggered to use either the descriptive LA or the PLA in the EAI dashboard to support their students.

1. Alert: Seven tutors reported that the OUA PLA either had or would trigger them to take action with a student if they had no other data (such as contact history or forum activity) to suggest the prediction was false. These potential actions varied. One referred a student to the Student Support Team, another had sent a general reminder email to the whole group, and five suggested they had, or would, attempt to contact the student in question either by phone or email. Only one tutor was able to provide a specific case [T24-H-03-03] of being alerted to an unknown issue with a student which, in their opinion, resulted in that student staying on the module.

2. Confirmation or reassurance: Twenty-one tutors indicated that they accessed the EAI dashboard at some point to confirm or reassure themselves that what they believed they already knew about a student, based on other information sources (such as non-submission of a TMA, concerning email or phone call, lack of tutorial attendance) was supported by the descriptive LA (VLE activity). Representative trigger comments included these: "I only look at it if there is a specific student I want to look at" [T08-C-07-06], "to confirm a hunch" [T10-C-XX-06], "to confirm a gut feeling" [T14-F-06-01], and "it would only be if I had worries, I might nip in" [T17-F-05-03]. Further, several of these tutors said they had accessed a student's specific VLE activity to give them confidence before calling or referring a student.

3. Curiosity: Five tutors indicated that they accessed the EAI dashboard and the PLA out of "curiosity" [T03-B-10-12] to see "how useful it might be" [T08-C-07-06], or to explore the features "from an academic point" [T30-J-18-03] in order "to guess what the algorithm it was using was" [T07-C-09-02] without having any particular use for it in mind.

4. At specific times: Nine tutors indicated that they had accessed the EAI dashboard after being prompted by something specific, such as an upcoming assessment point - "I found it interesting to see just before a TMA is due" [T03-B-1002] - or a reminder from the module management team via a forum or email "having a kind of kick to go and have a look at it was really good" [T16-F-10-02].

5. Randomly or ad hoc: Four tutors indicated that they had no particular trigger for looking at the EAI dashboard and their access was "not systematic, that's for sure" [T11-D-18-07]. One tutor accessed the data "when I'm bored" [T10C-XX-06].

\section{RQ4: What contribution did the EAl dashboard make to how tutors supported their students?}

When asked at interview, 19 tutors suggested that the EAI dashboard had made some limited contribution to the support they were able to offer their students, although none suggested that this contribution was significant. Nine indicated that they 
believed it had given them extra information that either confirmed existing views about students or helped "to identify students that were not engaging" [T12-D-09-01]. Six other tutors indicated that access to the EAI dashboard had provided them with data they could use to structure a challenging conversation and "does provide some additional evidence to kind of throw at students" [T26-H-25-07] in a dispute. Four tutors caveated their responses with contribution in time-specific periods (such as the start of the module) or with concerns about data confidentiality and tutor workload.

The remaining 11 tutors suggested that the EAI dashboard had made no contribution to the support they were able to offer their students. Responses were typically simple rejections such as "I don't think it has contributed at all" [T07-C-09-02], "I didn't find it really of any help this year" [T04-B-08-03], "I'm very ambivalent about it [...] I don't think it adds anything" [T10-C-XX-06], and "hasn't offered anything" [T28-J-37-04].

\section{Discussion and Analysis}

Ostensibly, the findings above concur with some results from previously published literature on tutor use of the EAI dashboard. These studies incorporated the Technology Acceptance Model (TAM; Davis, 1989) and the Academic Resistance Model (ARM; Piderit, 2000) to interview six self-selecting volunteer tutors (Herodotou et al., 2019a) and 20 "educational stakeholders" (representing roles in senior management [x6], student engagement [x4], tuition delivery [x6], and student support [x4]; Herodotou et al., 2019b) concluding that on the whole, tutors used OUA PLA to reaffirm their already-held suspicions about which of their students were "at risk" and identified an apparent paradox that despite tutors generally considering the EAI dashboard "useful" and "easy to use," actual tutor use was low, unsystematic, and infrequent (Herodotou et al. 2019a; 2019b). The authors argued that reasons for the low uptake amongst these two groups was likely found in insufficient tutor contractual arrangements mandating the use of LA, academic resistance to the use of PLA, a lack of time to engage in professional development to build trust and upskill data competencies, and no "strong evidence of the effectiveness of PLA to support students at risk" (Herodotou et al., 2019b, p. 91). A further study that interviewed eight more self-selecting OU tutors, using the same methodology, added that the "limited" use of the EAI dashboard was likely further explained by the "teaching beliefs about online teaching and learning and digital literacy" of the teachers (Herodotou et al., 2020, p. 12).

While these qualitative studies provide some insight into the use of the EAI dashboard by tutors at the OU, the utilized methodologies - TAM and ARM - can be critiqued for a narrow interpretation of the findings. Neither methodology allows much room for an interpretation that questions the actual value of the technology itself and both are preconditioned to present low usage take-up primarily in terms of the user being unable or ill-equipped to harness such self-evidently useful technologies.

We have borrowed from McCoy and Rosenbaum's (2019) concept of "shadow practices" to identify a different set of candidate mechanisms to explain this contradiction as well as other observed behaviours. A shadow practice is an example of "articulation work," "the continuous efforts required in order to bring together discontinuous elements - of organizations, of professional practices, of technologies — into working configurations" (Suchman, 1996, p. 407). That is, the work necessary to get (actual) work done. "Shadow practices" are described as interactions "both effective and unknown," which can be "undesired" and/or "unanticipated" and are "hidden from the designers and project leads" (McCoy \& Rosenbaum, 2019, p. 378). When a comparison of the end-users' anticipated practices (defined here by the design of the EAI dashboard) and the users' actual practices (as reported by the tutors) with the decision support system data dashboard (DSS-DD; in this case the EAI dashboard) reveal a difference or disconnect, "shadow practices," as a form of articulation work, emerge to fill this space and ultimately result in "the limited or non-use of DSS-DD for decision-making processes" (McCoy \& Rosenbaum, 2019, p. 371).

In social informatics approaches, the design of LA is not considered neutral but contains implicit or explicit values with the capacity to "influence the ways in which people do things" (Selwyn, 2019, p. 12) and "determine how actors behave" (Williamson, 2016, p. 125). The statement "OUA was primarily developed for teachers on an individual course to help them determine which students might be a risk on a week-by-week basis" (Herodotou et al., 2019b, p. 87) outlines that a set of anticipated, implicit user practices are present in the design of the EAI dashboard. For example, presenting data weekly suggests that frequent change in the status of the student is both probable and important to how tutors support students and that consequently it should be systemically monitored.

Further, the view of risk and its communication is instantiated in a traffic light system. This traffic light system to convey the PLA clearly draws the user to interpret this as the crucial indicator of a student being at-risk or not, despite other indicators, such as TMA and VLE data, also being present. However, the traffic light metaphor for communicating risk is not entirely unproblematic. For example, what level of risk does a tutor understand to be associated with each of the three categories? How does this relate to the risks the system uses to generate these indicators, presumably as deemed acceptable or unacceptable by the designers?

In this case, a comparison of anticipated practices (systematic and frequent access plus the generation of interventions prompted by the identification of at-risk students from the OUA PLA) against actual practices (unsystematic and infrequent 
access that declines over time and very limited generation of interventions prompted by the identification of at-risk students from the OUA PLA) led to the identification of three shadow practices, observed in the interviews, that can be viewed as either undesired or unanticipated:

1. Continuing the use of existing tools and approaches for supporting students

2. Predominant use of descriptive LA (rather than PLA) to identify, confirm, or reassure tutors about at-risk students

3. Focus on using LA to "get to know" the student cohort before the module starts and in the first few weeks

So, why did these shadow practices emerge and what drives them? We suggest three main candidate mechanisms that help to explain them: 1) a lack of trust in PLA, 2) the nature of de-contextualized data, and 3) that the EAI dashboard is trying to solve a problem that does not necessarily exist (see Figure 3).

\section{NON OR LIMITED USE OF EAI DASHBOARD}
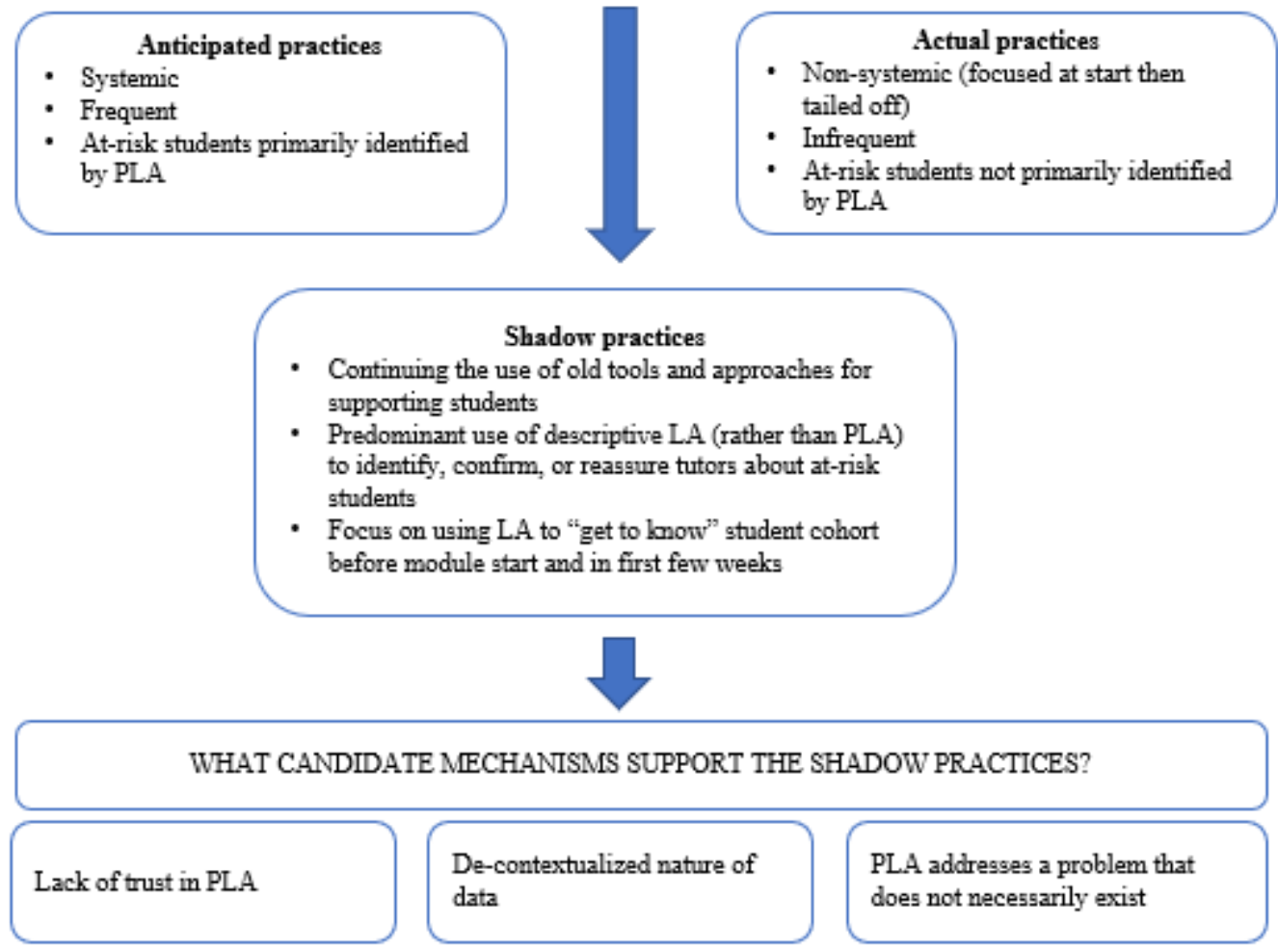

Figure 3. Application of the concept of shadow practices to the EAI dashboard.

The first candidate mechanism, driving two of the shadow practices in particular, is a lack of trust in the PLA. We suggest this may be due to both the complexity of interpreting and actioning the OUA PLA as well as confusion about how it was generated.

In maintaining the use of old tools and approaches for supporting students, research by Walker et al. (2019), completed prior to this study, established how tutors at the OU, before the introduction of the EAI dashboard, used the limited data tools already available to them. All respondents reported creating their own lists of students, often in offline spreadsheets or on paper, to allow them to identify those they considered at risk, typically, by combining disability flags, "last VLE login" dates, non-submission of assessments, and records of direct contact. These simple lists were considered useful for several reasons: (a) they were easy to use and understand, (b) they were considered trustworthy, (c) they were useful in getting to know the students, particularly in the first few months, and (d) they could be simply associated with an action. Tutors reported that the "diagnosis" of "at-risk" students, informed by these individually constructed and contextualized student lists, generally fell into three categories: health, time management, or academic unpreparedness. The tutors then decided whether and how to "intervene" The tutors then decided whether intervening was appropriate or not before considering the nature of any intervention (Walker et al., 2019). 
Although the tutors were not asked specifically, the act of personally contextualizing and customizing these student "atrisk" lists, coupled with their simplicity, seem to have made them enduringly attractive and worth returning to despite the availability of more fine-grained LA. This is an emerging theme in LA studies. For example, the LA features students said they would most commonly accept were simple deadline reminders, references to previous materials, and prompts to selfassessment and feedback (Schumacher \& Ifenthaler, 2018). The Principle of Customisation suggests LA interfaces should allow for users to "determine themselves which analytics they will attend to and in what way" (Wise \& Vytasek, 2017, p. 153).

The tutors were also generally unwilling to act solely on the OUA PLA because they did not understand how the predictions had been generated. Perhaps this is not surprising. Edwards (2018) points out how machine learning algorithms and the interaction between them in feedback loops soon become far too complex for their users - and even their programmers - to understand. Similarly, Ferguson et al. (2019) identified that an inability to scrutinize the validity of algorithms and complex data was an important concern for many international LA experts that they interviewed. The findings suggest that the STEM tutors referred primarily to the descriptive VLE and assessment LA because they understood it, trusted it, and could interpret it with confidence.

In line with Gašević et al. (2016), our findings also highlight how the de-contextualized emphasis on a "one-size-fits-all," at-scale, big data PLA model used by the EAI dashboard created problems for tutors when attempting to account for the vagaries of specific assessment strategies, differences in platform delivery, and particular pedagogies, and which appear to inform the emergence of the shadow practices. Since the modules examined here cover a wide variety of subject matter, learning designs do not typically conform to any one model. For example, some modules in this study were presented predominantly online (modules A, B, C, D, E, and F) while others are taught primarily via printed content and supported by online activities (modules H, I, and J). Also, module gradings are determined by different combinations of weightings applied to summative TMAs, which can also include substitutional assessment. Inevitably, modules in their first presentation were particularly problematic — since the model had not yet had time to "learn" the pathways that successful students took — but the number of false positive and negative flags across modules suggested that such issues such were not limited to first presentation modules alone. It is plausible that successful students could take any number of possible "pathways" through module materials depending on their own requirements that the model could not account for.

The development of the Student Relationship Engagement System (SRES) by the University of Sydney and its piloting by the University of Melbourne and the University of New South Wales, Sydney, emphasizes "teacher intelligence" and "small (but meaningful) data" through providing flexible mechanisms that allow teachers to select, and combine, the data sets most relevant to their own learning and teaching context and can therefore offer actionable insights. Qualitative research across these three institutions has revealed that many teachers found simple functions within SRES made the most sense to them. In this way, they were able to "remove some of the usual barriers to LA adoption such as one-size-fits-all approaches, opaque predictive algorithms, and a disconnect between analysis and action" (Arthars et al., 2019, p. 243), which our study has also found.

The important finding that tutors primarily accessed the EAI dashboard despite these contextual discrepancies before the first assessment point, reinforces a common and shared desire for more information about students early in the module cycle and was also observed by Walker et al. (2019). The observation that tutors primarily sought this information from the descriptive LA is partly explained by their understanding that the OUA PLA algorithm only takes on any form of reliability after the submission of the first assessment piece. Before the first assessment point, the OUA PLA is considered unreliable; after the first assessment point, it is considered largely superfluous and does not therefore contribute significantly to solving either of these two problems.

The Supporting Higher Education to Integrate Learning Analytics (SHEILA) framework - developed with input from 51 European HEIs to provide guidance on implementing LA — points to the crucial question, "which problems are to be addressed by LA?" (SHEILA, 2018) as one of the first policy considerations. Kling (2007) also highlights the importance of including robust "discovery processes" in the design of social-technical systems. Other studies that have employed social-informatics approaches to research developments in course materials have also reported the relative dis/empowerment of academics and academic-related staff to satisfy organizational needs and priorities, or technical platform requirements (White \& White, 2016). Since LA implementations draw heavily on technological infrastructure, financial resources, and human resources (Tsai et al., 2018), to ensure they are utilized, it seems crucial that they respond to the actual needs of the social actors who are the end users.

\section{CONCLUSION}

This study has outlined the findings from a project that employed a social informatics approach to evaluate the practice of 30 tutors in the STEM faculty at the OU in the implementation of the EAI dashboard during the 2017-2018 academic year. The discussion section identifies, through the application of the concept of "shadow practices" (McCoy \& Rosenbaum, 2019), 
three main candidate mechanisms that help to explain why the participating tutors used the EAI dashboard in the ways that they did.

This study does not seek to advocate the use of the EAI dashboard, LA, or PLA, and the authors, in their roles in the STEM faculty, were not involved in either its development or implementation. However, it is our hope that if readers from other institutions are planning similar LA implementations, they consider the end user as a social actor, and therefore may find elements of this discussion applicable in their own contexts. To avoid living in an "LA (P)LA Land" — a land of unrealized potential - it seems important that LA implementations incorporate social-informatics approaches as a valuable alternative to the "high spirited but largely a priori promotions of technologies that occasionally work well for people, occasionally are valuable, are sometimes abandoned, are sometimes unusable, and thus incur predictable waste and inspire misplaced hopes" (Kling, 2007).

\section{Declaration of Conflicting Interest}

The authors declare no potential conflicts of interest with respect to the research, authorship, and/or publication of this article

\section{Funding}

The authors declare no financial support for the research, authorship, and/or publication of this article.

\section{References}

Agnihotri, L., \& Ott, A. (2014). Building a student at-risk model: An end-to-end perspective from user to data scientist. In J. Stamper et al. (Eds.), Proceedings of the $7^{\text {th }}$ International Conference on Educational Data Mining (EDM2014), 4-7 July 2014, London, UK (pp. 209-212). International Educational Data Mining Society. Retrieved from http://citeseerx.ist.psu.edu/viewdoc/download?doi=10.1.1.660.2885\&rep=rep1\&type=pdf

Arthars, N., Dollinger, M., Vigentini, L., Liu, Y.-T., Kondo, E., \& King, D. (2019). Empowering teachers to personalise learning support. In D. Ifenthaler, J. Yau, \& D. Mah (Eds), Utilising learning analytics to support study success. Cham, Switzerland: Springer. https://doi.org/10.1007/978-3-319-64792-0_13

Bartimote, K., Pardo, A., \& Reimann, P. (2019). The perspective realism brings to learning analytics in the classroom. In J. M. Lodge, J. C. Horvath \& L. Corrin (Eds.), Learning analytics in the classroom: Translating learning analytics research for teachers. Abingdon-on-Thames, UK: Routledge.

Braun, V., \& Clarke, V. (2006). Using thematic analysis in psychology. Qualitative Research in Psychology, 3(2), 77-101. https://doi.org/10.1191/1478088706qp063oa

Calvert, C. (2014). Developing a model and applications for probabilities of student success: A case study of predictive analytics. Open Learning: The Journal of Open, Distance and e-Learning, 29(2), 160-173. http://doi.org/10.1080/02680513.2014.931805

Castaneda, L., \& Selwyn, N. (2018). More than tool? Making sense of the ongoing digitizations of higher education. International Journal of Education Technology in Higher Education, 15(22), 1-10. https://doi.org/10.1186/s41239018-0109-y

Clow, D. (2013). An overview of learning analytics. Teaching in Higher Education, 18(6), 683-695. https://doi.org/10.1080/13562517.2013.827653

Conole, G. (2012). Designing for learning in an open world. Dordrecht, Netherlands: Springer.

Creanor, L., \& Walker, S. (2012). Learning technology in context: A case for the sociotechnical interaction framework as an analytical lens for networked learning research. In L. Dirckinck-Holmfeld, V. Hodgson, \& D. McConnell (Eds.), Exploring the pedagogy and practice of networked learning (pp. 173-187). London, UK: Springer. https://doi.org/10.1007/978-1-4614-0496-5_10

Dalziel, J., Conole, G., Wills, S., Walker, S., Bennett, S., Dobozy, E., Cameron, L., Badilescu-Buga, E., \& Bower, M. (2016). The Larnaca declaration on learning design. Journal of Interactive Media in Education, 1(7), 1-24. https://doi.org/10.5334/jime.407

Daniel, B. (2015). Big data and analytics in higher education: Opportunities and challenges. British Journal of Educational Technology, 46(5), 904-920. https://doi.org/10.1111/bjet.12230

Davis, F. (1989). Perceived usefulness, perceived ease of use, and user acceptance of information technology. MIS Quarterly, 13(3), 319-340. https://doi.org/10.2307/249008 
Edwards, P. (2018). We have been assimilated: Some principles for thinking about algorithmic systems. In U. Schultze, M. Aanestad, M. Mähring, C. Østerlund, \& K. Riemer (Eds.), Living with monsters? Social implications of algorithmic phenomena, hybrid agency, and the performativity of technology. Proceedings of the Working Conference on Information Systems and Organizations (IS\&O 2018), 11-12 December 2018, San Francisco, CA, USA (pp. 19-27). IFIP Advances in Information and Communication Technology, vol 543. Cham, Switzerland: Springer. https://doi.org/10.1007/978-3-030-04091-8 3

Ferguson, R., Clow, D., Griffiths, D., \& Brasher, A. (2019). Moving forward with learning analytics: Expert views. Journal of Learning Analytics, 6(3), 43-59. http://doi.org/10.18608/jla.2019.63.8

Foster, E. (2015). What have we learnt from implementing learning analytics at NTU? Retrieved from https://www.yumpu.com/en/document/view/54413096/what-have-we-learnt-from-implementing-learning-analytics-atntu

Gašević, D., Dawson, S., Rogers, T., \& Gašević, D. (2016). Learning analytics should not promote one size fits all: The effects of instructional conditions in predicting learning success. Internet and Higher Education, 28, 68-84. https://doi.org/10.1016/j.iheduc.2015.10.002

Herodotou, C., Hlosta, M., Boroowa, A., Rienties, B., Zdrahal, Z., \& Mangafa, C. (2019c). Empowering online teachers through predictive learning analytics. British Journal of Educational Technology, 50(6), 3064-3079. https://doi.org/10.1111/bjet.12853

Herodotou, C., Rienties, B., Boroowa, A., Zdrahal, Z., \& Hlosta, M. (2019a). A large-scale implementation of PLA in higher education: The teacher's role and perspective. Educational Technology Research and Development, 67, 1273-1306. https://doi.org/10.1007/s11423-019-09685-0

Herodotou, C., Rienties, B., Hlosta, M., Boroowa, A., \& Mangafa, C. (2020). The scalable implementation of predictive learning analytics at a distance learning university: Insights from a longitudinal case study. The Internet and Higher Education, 45, 1-3. https://doi.org/10.1016/j.iheduc.2020.100725

Herodotou, C., Rienties, B., Verdin, B., \& Boroowa, A. (2019b). Predictive Learning Analytics "at scale": Towards guidelines to successful implementation in higher education based on the case of The Open University UK. Journal of Learning Analytics, 6(1), 85-95. https://doi.org/10.18608/jla.2019.61.5

Hidalgo, R. (2018). Analytics for action: Using data analytics to support students in improving their learning outcomes. In G. Ubachs \& L. Konings (Eds.), The envisioning report for empowering universities (2nd ed.), (pp. 6-8). Maastricht: EADTU. Retrieved from https://tinyurl.com/envisioning-report

Hu, Y., Lo, C., \& Shih, S. (2014). Developing early warning systems to predict students' online learning performance. Computers in Human Behaviour, 36, 469-478. https://doi.org/10.1016/j.chb.2014.04.002

Jivet, I., Scheffel, M., Spect, M., \& Drachsler, H. (2018). License to evaluate: Preparing learning analytics dashboards for educational practice. Proceedings of the $8^{\text {th }}$ International Conference on Learning Analytics and Knowledge (LAK '18), 5-9 March 2018, Sydney, NSW, Australia (pp. 31-40). New York: ACM. https://doi.org/10.1145/3170358.3170421

Klein, C., Lester, J., Rangwala, H., \& Johri, A. (2019). Learning analytics tools in higher education: Adoption at the Intersection of institutional commitment and individual action. The Review of Higher Education, 42(2), 565-593. Baltimore, MD: John Hopkins University Press. https://doi.org/10.1353/rhe.2019.0007

Kling, R. (2007). What is social informatics and why does it matter? The Information Society, 23(4), 205-220. https://doi.org/10.1080/01972240701441556

Knight, S., \& Buckingham Shum, S. (2017). Theory and learning analytics. In C. Lang, G. Siemens, A. Wise, \& D. Gašević (Eds.), The handbook of learning analytics, (pp. 17-22). Beaumont, AB: Society for Learning Analytics Research (SoLAR). https://doi.org/10.18608/hla17

Kop, R., Fournier, H., \& Guillaume, D. (2017). A critical perspective on learning analytics and educational data mining. In C. Lang, G. Siemens, A. Wise, \& D. Gašević (Eds.), The handbook of learning analytics, (pp. 319-326). Beaumont, AB: Society for Learning Analytics Research (SoLAR). https://doi.org/10.18608/hla17

Kuzilek, J., Hlosta, M., Herrmannova, D., Zdrahal, Z., \& Wolff, A. (2015). OU analyse: Analysing at-risk students at The Open University. Learning Analytics Review, LAK15-1, 1-16. Retrieved from https://oro.open.ac.uk/42529/1/_userdata_documents4_ctb44_Desktop_analysing-at-risk-students-at-openuniversity.pdf

Lamb, R., \& Kling, R. (2003). Reconceptualising users as social actors in information systems research. MIS Quarterly, 27, 197-235. https://doi.org/10.2307/30036529

Lodge, J., Horvath, J., \& Corrin, L. (2019). Introduction. In J. M. Lodge, J. C. Horvath \& L. Corrin (Eds.), Learning analytics in the classroom: Translating learning analytics research for teachers. Abingdon-on-Thames, UK: Routledge. 
Long, P., \& Siemens, G. (2011). Penetrating the fog: Analytics in learning and education. Educause Review,

September/October, 31-40. Retrieved from https://er.educause.edu/ /media/files/article-downloads/erm1151.pdf

Maguire, M., \& Delahunt, B. (2017). Doing a thematic analysis: A practical, step-by-step guide for learning and teaching scholars. All Ireland Journal of Higher Education 9(3), 33501-33514. Retrieved from

https://ojs.aishe.org/index.php/aishe-j/article/view/335

McCoy, C., \& Rosenbaum, H. (2019). Uncovering unintended and shadow practices of users of decision support systems decision support in higher education institutions, Journal of the American Association for Information Science and Technology, 70(4), 370-384. https://doi.org/10.1002/asi.24131

Nguyen, Q., Rienties, B., Toetenel, L., Ferguson, F., \& Whitelock, D. (2017). Examining the designs of computer-based assessment and its impact on student engagement, satisfaction, and pass rates. Computers in Human Behaviour, 76, 703-714. https://doi.org/10.1016/j.chb.2017.03.028

Olney, T., Rienties, B., \& Toetenel, L. (2019). Gathering, visualising and interpreting learning design analytics to inform classroom practice and curriculum design: Learning analytics in the classroom. In J. M. Lodge, J. C. Horvath \& L. Corrin (Eds.), Learning analytics in the classroom: Translating learning analytics research for teachers, (pp. 71-92). Abingdon-on-Thames, UK: Routledge.

Orlikowski, W., \& Gash, D. (1994). Technological frames: Making sense of information technology in organizations. ACM Transactions on Information Systems, 12(2) 174-207. https://doi.org/10.1145/196734.196745

Piderit, S. (2000). Rethinking resistance and recognizing ambivalence: A multidimensional view of attitudes toward an organizational change. The Academy of Management Review, 25(4), 783-794. https://doi.org/10.2307/259206

Rienties, B., Boroowa, A., Cross, S., Kubiak, C., Mayles, K., \& Murphy, S. (2016). Analytics4Action evaluation framework: A review of evidence-based learning analytics interventions at Open University UK. Journal of Interactive Media in Education, 1(2), 1-12. https://doi.org/10.5334/jime.394

Rienties, B., Herodotou, C., Olney, T., Schencks, M., \& Boroowa, A. (2018). Making sense of learning analytics dashboards: A technology acceptance perspective of 95 teachers. The International Review of Research in Open and Distributed Learning, 19(5). https://doi.org/10.19173/irrodl.v19i5.3493

Sawyer, S., \& Hartswood, M. (2014). Advancing social informatics. In P. Fichman \& H. Rosenbaum (Eds.), Social informatics: Past, present and future (pp. 197-209). Newcastle upon Tyne, UK: Cambridge Scholars Publishing.

Schumacher, C., \& Ifenthaler, D. (2018). Features students really expect from learning analytics. Computers in Human Behaviour, 78, 397-407. https://doi.org/10.1016/j.chb.2017.06.030

Schwendimann, B., Rodríguez-Triana, M. J., Vozniuk, A., Prieto, L. P., Shirvani Boroujeni, M., Holzer, A., Gillet, D., \& Dillenbourg, P. (2017). Perceiving learning at a glance: A systematic literature review of learning dashboard research. IEEE Transactions on Learning Technologies, 10(1), 30-41. https://doi.org/10.1109/TLT.2016.2599522

Sclater, N., Peasgood, A., \& Mullan, J. (2016, April 19). Learning analytics in higher education: A review of UK and international practice. Jisc. Retrieved from https://analytics.jiscinvolve.org/wp/2016/04/19/learning-analytics-inhigher-education-a-review-of-uk-and-international-practice/

Selwyn, N. (2019). What's the problem with learning analytics? Journal of Learning Analytics, 6(3), 11-19. https://doi.org/10.18608/jla.2019.63.3

Shacklock, X. (2016). From bricks to clicks: The potential of data and analytics in higher education. Policy Connect. Higher Education Commission. Retrieved from https://www.policyconnect.org.uk/hec/research/report-bricks-clicks-potentialdata-and-analytics-higher-education

SHEILA. (2018). Supporting higher education to integrate learning analytics framework. Retrieved from https://sheilaproject.eu/wp-content/uploads/2018/08/SHEILA-framework_Version-2.pdf

Simpson, O. (2006). Predicting student success in open and distance learning. Open Learning: The Journal of Open, Distance and e-Learning, 21(2), 125-138. https://doi.org/10.1080/02680510600713110

Slade, S. \& Boroowa, A. (2014). Policy on ethical use of student data for learning analytics. Milton Keynes, UK: The Open University. Retrieved from https://help.open.ac.uk/documents/policies/ethical-use-of-student-data

Suchman, L. (1996). Supporting articulation work. In R. Kling (Ed.), Computerization and controversy: Value conflicts and social choices ( $2^{\text {nd }}$ ed), (pp. 407-423). San Francisco, CA: Morgan Kaufmann.

Tanes, Z., Arnold, K., King, A., \& Remnet, M. (2011). Using signals for appropriate feedback: Perceptions and practices. Computers \& Education, 57(4), 2414-2422. https://doi.org/10.1016/j.compedu.2011.05.016

TEF. (2019). Teaching excellence and student outcomes framework. Retrieved from https://www.officeforstudents.org.uk/advice-and-guidance/teaching/what-is-the-tef/

Tsai, Y.-S., Moreno-Marcos, P., Jivet, I., Scheffel, M., Tammets, K., Kollom, K., \& Gašević, D. (2018). The SHEILA framework: Informing institutional strategies and policy processes of learning analytics. Journal of Learning Analytics, 5(3), 5-20. https://doi.org/10.18608/jla.2018.53.2 
van Harmelen, M., \& Workman, D. (2012). Analytics for learning and teaching. Technical Report in CETIS Analytics Series, vol. 1, no. 3. Bolton, UK: CETIS.

Walker, S., \& Creanor, L. (2009). The STIN in the tale: A sociotechnical interaction perspective on networked learning. Journal of Educational Technology and Society, 12(4), 305-316. Retrieved from https://citeseerx.ist.psu.edu/viewdoc/download?doi=10.1.1.303.6882\&rep=rep1\&type=pdf

Walker, S., Olney, T., Wood, C., Clarke, A., \& Dunworth, M. (2019). How do tutors use data to support their students? Open Learning: The Journal of Open, Distance and e-Learning, 34, 118-133. https://doi.org/10.1080/02680513.2018.1554476

White, S., \& White, S. (2016). Learning designers in the "third space": The socio-technical construction of MOOCs and their relationship to educator and learning designer roles in HE. Journal of Interactive Media in Education, 2016(1) 1-12. https://doi.org/10.5334/jime.429

Williamson, B. (2016). Digital education governance: Data visualization, predictive analytics, and real-time policy instruments. Journal of Education Policy, 31(2), 123-141. https://doi.org/10.1080/02680939.2015.1035758

Wise, A., \& Vytasek, J. (2017). Learning analytics implementation design. In C. Lang, G. Siemens, A. Wise, \& D. Gašević (Eds.), The handbook of learning analytics, (pp. 151-160). Beaumont, AB: Society for Learning Analytics Research (SoLAR). https://doi.org/10.18608/hla17 